\title{
The Concierge. Tradition, Obsolescence and Innovation in Tourism
}

\author{
Nicola Bellini*, Laetitia Convert ${ }^{* *}$
}

\begin{abstract}
In the hotel industry the concierge is a key role placed at the customer-supplier interface, managing some of the most important service encounters in the guest's hospitality experience. The paper discusses the impact of new technologies that challenge, but also contribute to reshape, the importance of this role. The outsourcing trend is another threat to the traditional concierge, which is made possible in the new scenario. A new balance between technological and human factors may emerge out of the complex transformation process that the hospitality industry is presently undergoing.
\end{abstract}

Keywords: Global Tourism; Concierge; Innovation; Obsolescence; Outsourcing; Hospitality Industry; Global Competition

\section{Service Innovation and Hospitality Industry}

Service innovation is a fundamental factor of competitiveness also in tourism, impacting on companies' medium and long term performance, if not necessarily also on short term results (Martínez-Román et al., 2015; Campo et al., 2014; Mattsson \& Orfila-Sintes, 2014). Increasingly tourism studies have paid attention to innovation in order to capture the specificities of this industry with regard both to the wider theme of innovation in services and to the even wider research of innovation.

In particular, an emerging literature has focused on hotels as the arena of complex innovation processes, where internal and external factors interact (Nieves \& Segarra-Ciprés, 2015; Tang et al., 2015). Their interpretation requires a critical use of the concepts that have been developed so far mostly within the manufacturing sectors. E.g., the adequacy of the 'absorption capacity' concept could be questioned in hospitality, notwithstanding the necessarily 'open' character of innovation in this industry (Thomas \& Wood, 2014). Hotels are a privileged field with regard to several key theoretical issues in contemporary management, such as the nature of customer engagement and the co-creation processes, the experience economy, the 'service-dominant' logic (Shaw et al., 2011; Chathoth et al., 2016).

\footnotetext{
* Director, Tourism Management Institute, La Rochelle Business School (bellinin@esc-larochelle.fr)

** Research Assistant, Tourism Management Institute, La Rochelle Business School (convert113@edu.esc-larochelle.fr)
}

Bellini, N., \& Convert, L. (2016). The Concierge. Tradition, Obsolescence and Innovation in Tourism, Symphonya. Emerging Issues in Management (symphonya.unimib.it), 2, 17-25. 
Repeatedly all conceptual contributions suggest the need for empirical works. Accordingly, this paper intends to focus on the innovative trends concerning one specific role in the hotel industry, the concierge.

His historical importance can hardly be underestimated and combines with a paradigmatic relevance also from the theoretical point of view, as the concierge is crucially placed at the customer-supplier interface and manages some of the most important service encounters in the guest's hospitality experience (Adler \& Gordon, 2013). Traditionally the concierge service has been crucial in defining the image and the reputation of the hotel and of its brand as well as in ensuring the customers' loyalty. This paper investigates the impact that new technologies in the hospitality industry have on this role, either substituting for at least some of the traditional functions or forcing new forms of integration between technological and human factors.

This paper is also based on the results of an original survey based on forty-four in-depth interviews (through questionnaire) with professional concierges from four and five stars hotels, realised in 2015 in France and Canada.

\section{The Concierge}

A hotel concierge has been for centuries, in many respects, the most outstanding interpreter of luxury service in hospitality. He is always in contact with the guest during his/her stay and is a key interlocutor for the general manager thanks to his ability to provide services, information and advices in real time to his guests. The role of concierge is based on a 'capital of autochthony', i.e. on networks of relations that are built over time (the address book of local 'trustworthy' providers) and that have made him/her irreplaceable (Menoux, 2012). In our survey, interviewees selected 'empathy', 'communication skills' and 'level of knowledge and service expertise' as the main qualities that are required to be a good concierge.

In the current hospitality industry, the hotel concierge represents a department on its own, almost a 'firm into another firm', and has the responsibility of welcoming guests, advise them and giving them information (Mills et al., 2009; Kasner). Hotel concierges are part of 'uniformed services', including porters, doorpersons and valets. Concierges manage both doorpersons and valets and are under the control of the chef concierge.

Concierge departments represent a real mark of differentiation towards midscale hotels, such as three star hotels or less, where normally there is no such service. In these lower scale hotels, receptionists flexibly perform also at least some of the tasks of the concierge. In fact, the organisational convergence with the front office is a more general trend. Today, most hotels incorporate the concierge department into the Guest service or Room divisions departments that welcome guests and are in charge of the guests' registration process, check in and check out. In that sense, the functions of concierges are seen as an extension of reception staff duties and concierges are not anymore controlled by a chef concierge but by the front office manager. Thus, in some hotels, especially in Europe, both front office and concierge departments are under the control of the front office manager. 
A peculiar aspect of this job is the sense of identity that is reflected in the role of the Clefs d'Or association. One can identify a Clefs d'Or concierge by the little gold keys he/she wears on the uniform. The association was established in 1929 and, at the beginning, it included only luxury hotels of Paris. Today, the association reaches more than 3000 members and represents the organisation of professional, highly qualified hotel concierges worldwide with concierges who work together to provide the best attentive service to their guests. In order to possess these famous little keys, concierges have to work in the hospitality industry for five years, including three years of concierge services. Clefs d'Or membership is perceived as the top professional accomplishment in a concierge career (Mills et al., 2009). On the contrary, educational programs do not often focus on this profile, with one remarkable exception, i.e. the Institut de Conciergerie Internationale, a private institution located in Paris, offering 3-year certified bachelor programs.

The role of a concierge can also be seen as concerning the establishment and management of a relationship with guests. In other words, we may consider concierges as quintessential (and ante litteram) example of a relational approach to customers (Frochot and Légoherel, 2014, ch. 5). This relationship is based on trust that is built upon a sequence of events showing the concierge ability to fully understand the customers' needs and wishes and to provide the most appropriate response to them. This sequence may contribute decisively to the guest's hotel experience and satisfaction, based on the perception of the unique quality of the assistance received by the concierge. Thus, the quality of concierge services must be considered as one of the differentiating elements of a luxury hotel.

\section{The Impact of Technological Innovation}

Today contemporary concierges face and need to deliver value to an empowered customer, an imperative that is crucial to modern corporations and their employees (Brondoni \& Pironti, 2015). Technology is the main source of empowerment of the 'post-modern' tourist. Thanks to mobile internet, a guest can immediately check the information or advice received by the concierge and compare with the information and advices that he/she can autonomously find on the web. Technology threatens to substitute for them and for their main knowledge assets (Menoux, 2012).

This may happen in several ways. The most obvious one is the substitution of the human interface with the availability of analogous information through computers and mobile interfaces. These have the advantage of providing instant, multilanguage assistance that is available any time, day and night, in ways that are familiar to a large majority of customers. Independent companies offer mobile concierge services dedicated to hotels. Alternatively, similar services are developed autonomously by large groups with a variety of solutions, like Accor's Novotel Virtual Concierge, launched in 2013 in partnership with leading hospitality technology group Monscierge, or Hyatt's Twitter based 'HyattConcierge' service, launched in 2010 (Levere, 2011).

The presence of new technologies in hotels is rapidly increasing. New benchmarks of 'digitally enhanced hotels' are emerging, like the recently opened Renaissance New York Midtown Hotel, with a wide and spectacular use of 
interactive screens throughout the lobby and common areas. Robots are being introduced in major hotel chains in variety of roles (bartenders, receptionists, room service delivery etc.) and also as concierge. Hilton (in cooperation with IBM Watson) introduced a humanoid robot, based on a cognitive computing technology platform, a combination of different application programming interfaces (Dialog, Speech to Text, Text to Speech and Natural Language Classifier) and a cognitive travel recommendation engine. The 'Connie' robot is able to greet guests upon arrival and to answer questions about hotel amenities, services and hours of operation ${ }^{1}$. What all these experiences have in common is that they aim at providing newer generations of customers with additional elements of experience, that are characterised by 'fun' and a gaming approach as much as by the wealth and timeliness of the information provided.

The introduction of these technologies has often been associated with an opportunity to reduce costs, as the salary of an experienced concierge could be far from irrelevant. Also the possibility of 'up-selling' is mentioned as attractive for some hotel managers (Rico, 2016).

These views fit quite well in the growing 'obsession' for the financial dimensions of hotel management, which has characterised recent years (Wang \& Wang, 2009) and which leads to consider concierge departments in terms of revenue generation (with an underestimation of their impact on loyalty and brand). According to the majority of our interviewees (more than 50\%), technology without human 'touch' inescapably means a decreasing level of service quality. As a matter of fact, even focusing on costs, new technologies require a significant amount of investments to be both developed and maintained at the state-of-the-art (and even more, if one is looking for 'wow effects' on the customer). Furthermore, the lag time between technology expenditures and payback can be lengthy (Bilgihan et al., 2016). To this we must add the knowledge and expertise needed to fully and creatively exploit new technologies (and therefore the costs of training and re-training the staff). All these elements clearly lead to emphasise an advantage for large groups over independent hotels.

Rather than a mere, old-fashioned case of labor substitution, new technologies seem to challenge hotel management towards integration between technologies and human factors. In our survey, professionals showed a sincere awareness of the importance of the availability of updated technological support. Nonetheless, one third of the interviewees were categorical on the importance of not adapting to new technologies and nearly the half of them argued that being up to date with technologies is not the key and it is rather crucial to focus on human assets, such as experience, knowledge and, above all, relations with local partners. In other words, a clear divide emerges: on the one hand, some are 'future-oriented' and see new technologies as a good way for hotels to attract and retain 'Millennials' (of course, to the extent that this complements the physical presence of the concierge); on the other hand, for a 'conservative', tradition-oriented opinion all is about customer service, keeping high standards and qualified people by being always on site in order to be quickly responsive.

The integration between technology and human factors is threefold. Firstly, the independent use of mobile apps (or of devices made available to the customers by the hotel, such as in-room tablets) relieves the concierge from some simple tasks 
such as reservations, as the guest can perform these at any time. Also a large majority of our interviewees agreed that in the future basics services such as restaurant reservations, emailing, directions, car rental reservations, airport transfer bookings or boarding passes printing could be entirely automatized.

Secondly, concierges in variety of situations could use digital tools, especially when a higher level of service accuracy can be reached (e.g. by delivering to the customer the printout of a restaurant's updated menu). Ad hoc software to assist concierges is now available on the market.

Thirdly and more importantly, the role of the concierge can be focused on confirming and reassuring the guest with regard to the information that he/she has independently retrieved (therefore emphasising the trust element in the relationship), and possibly on complementing that information with personalised, informal suggestions, updates etc. In this case the impact of the concierge on the customer's decision making is fully reconfirmed.

This approach may also lead to a specialisation of concierge services provided by hotels. E.g. Westin Hotels \& Resorts has focused on the guests' physical activities and provides 'concierges' specialised in supporting the guests' surfing, skiing, hiking and cycling. By 2016 Westin had 200 'Run Concierges' globally.

Internet-based 'virtual concierge' approaches may indeed allow for a much wider scope of interaction with guests. An enlightening example is provided by Opus Hotel in Vancouver, where guest rooms are grouped by 'room personality'. The hotel's website has a feature to help guests determine their personality type, defined on the basis of some lifestyle variables. The result is a micro-segmentation of the customers that facilitates the provision of specific local recommendations (on dining, entertainments, shopping etc.).

An important frontier of innovation concerns social networks. Visibility on social networks is of course a way to promote the e-reputation of the hotel and of its services, but is also a way to enhance the guest's experience, by both anticipating and prolonging the interaction with the customers. Social networks may provide an early opportunity to contact and to interact with the customer in order to prepare the stay as well as the possibility to send post-departure notes, like a personalised 'thank you', encouragement to share images and experiences on social networks, information about events and news that may be of interest to the customer in the perspective of a comeback. Overall, some important questions can be raised on the ability of the available human resources to comply with the new 'rules', within a reorganised front-office structure (Montargot, 2016). This implies a thorough reappraisal of the traditional training of a concierge. For 'pre-Internet' concierges the adaptation may be neither easy nor well accepted. Large hotel groups have implemented programs to increase of their ability to use the most recent devices, in face of highly 'tech-savvy' guests, and to re-interpret their role accordingly (Adler \& Gordo, 2013, p. 63).

\section{The Concierge Outside the Hotel}

An equally important trend, that technologies contribute to make possible, is the outsourcing of concierge services to specialised firms. It is an option that is of 
interest for all those establishments that are engaged in cost-reduction strategies, a major issue in contemporary hospitality industry (Wang \& Wang, 2009).

This trend is not taking place without doubts on its sustainability and impacts. On the one hand, there are, of course, advantages in terms of costs and flexibility. If the employees of the contractor are present in the hotel, the customer will hardly distinguish them from the hotel's staff. They will also be able to respond in a professional way to the requests of customers.

On the other hand, private concierges are often linked by contracts with specific sightseeing companies, restaurants, venues that pay them a commission. On the contrary, hotel concierges have no obligation other than to the hotel, its brand and the guests. Furthermore, private concierges have no 'memory' of the guests, they cannot build a lasting relationship with the hotel customers and they often are not sufficiently involved in the hotel's operations. Overall, one should expect that their contribution as differentiator is less significant than the one provided by hotel concierges. Our survey confirms this perception, as $80 \%$ of our interviewees rejected the idea that private concierge companies would be a real threat to their position.

Parallel to (and partially integrated with) the outsourcing trend, there is however the emergence of new markets for concierge services: "guest-oriented service standards set by concierges have transcended the hotel industry to be embraced by other businesses" (Withiam, 1993). Once again, tourism 'exports' business ideas and service models to other sectors (Bellini \& Brondoni, 2016).

Roles named as 'concierge' can be found in apartment buildings, malls, companies, and hospitals. Concierge services may be acquired to serve the clients' business-related needs (such as making a reservation for a business trip, setting up a meeting facility etc.), but also to take care of extra-work, private activities. 'Corporate concierges' are hired to rent a car service, reserve a restaurant table or a theatre ticket, planning a personal event etc.

It is a phenomenon that is especially diffused in the United States and rapidly growing in Europe. While originally the availability of the corporate concierge was considered mainly a benefit for higher ranking executives and special customers, in recent years the corporate concierge services, provided by an increasing number of specialised companies, have been extended to wider groups of clients and increasingly 'democratised', offering a variety of services for the employees such as babysitting, grocery delivery, health care etc. In this respect the benefit is seen as a way to facilitate personal life and reach a better balance with the professional one, therefore diminishing absenteeism, increasing productivity and strengthening loyalty.

The role of private concierge companies cannot be easily dismissed. Some of these companies have reached a significant size. The market leader, John Paul, founded in Paris in 2008 and merged with LesConcierges in 2015, sells for approximately 50 millions euros and operates with more than 1000 staff globally, using a proprietary Customer Relationship Management and data platform based on behavioral profiling and personalisation. The company works both in hospitality and for large companies, managing their premium customer relations. Some of their services are integrated into a major credit card premium benefits. In 2016 the group Accor has acquired this company. 


\section{Conclusions and Emerging Trends}

The role of the concierge is placed at the crossroads of the complex transformations that the hospitality industry is presently undergoing. Tradition identifies the concierge as one of the elements that delivers value and quality to the customers and builds the distinctiveness of the service provided to the hotel's guest, therefore contributing to its non-price competitiveness. In a time of emerging 'experiential luxury' (Abtan et al., 2014), the interaction between the guest and the concierge is likely to be one of the most relevant constituents of the overall customer experience, especially in the higher value segments of the hospitality market.

This role is clearly challenged by innovation trends in the industry and especially by those directly or indirectly related to technology. The risk of obsolescence is the result of the two combined threats of the substitution of humans with devices and robots, one the one hand, and of the outsourcing to specialised companies providing the concierge service, on the other. Although cost motivations are often quoted as the main incentive to follow those paths, one cannot dismiss the fact that alternative strategies to in-house concierge departments may also be the opportunity to renew the customer experience in the service encounter and co-creation. Furthermore, the impact of the increasing size and capabilities of the providers allows for a scope of the assistance provided to customers, which is wider both in time and space, and for a cross-fertilisation, which derives from their accumulation of experiential knowhow in very different sectors.

A reasonable outcome of these processes may be in the identification of some new balance between technological power and human touch and between in-house embeddedness and wider competencies. Notwithstanding the many attempts to provide professionals with some foresight on the "hotel of the future", there is no unambiguous indication of how this will develop, or perhaps one could argue that there may be a range of different possible outcomes that will coexist and be viable to the extent that they will be consistent to corporate strategies and really contribute to the delivered value and to their perceived distinctiveness. In other words, the fate of the concierge is only a component of the rapid evolution of the hospitality industry, of tourism and of its relation with the rest of the economy. But, for sure, it is an enlightening one, which research should monitor more closely than it has done so far.

\section{Bibliography}

Abtan, O. et al. (2014). Shock of the New Chic: Dealing with the New Complexity in the Business of Luxury. Boston, MA: The Boston Consulting Group.

Adler, H., \& Gordon, S. (2013). An Analysis of the Changing Roles of Hotel Concierges. Journal of Tourism and Hospitality Management, 1 (2), 53-66.

Bellini, N., \& Brondoni, S.M. (2016). Ouverture de Global Tourism in Global Markets, Symphonya. Emerging Issues in Management (symphonya.unimib.it), 1, 1-6.

http://dx.doi.org/10.4468/2016.1.01ouverture 
Bilgihan, A., Okumus, F., Nusair, K., \& Kwun, D. (2011). Information technology applications and competitive advantage in hotel companies. Journal of Hospitality and Tourism Technology, 2 (2), 139-154.

http://dx.doi.org/10.1108/17579881111154245

Brondoni S.M., \& Pironti M. (2015). Ouverture de 'Design Management, Product Engineering and Global Competition', Symphonya. Emerging Issues in Management (symphonya.unimib.it), 2, 112.

http://dx.doi.org/10.4468/2015.2.01ouverture

Chathoth, P., Ungson, G., Harrington, R., \& Chan, E. (2016). Co-creation and higher order customer engagement in hospitality and tourism services. A critical review. International Journal of Contemporary Hospitality Management, 28 (2), 222-245.

http://dx.doi.org/10.1108/IJCHM-10-2014-0526

Campo, S., Díaz, A.M., \& Yagüe, M.J. (2014). Hotel innovation and performance in times of crisis. International Journal of Contemporary Hospitality Management, 26 (8), 1292-1311. http://dx.doi.org/10.1108/IJCHM-08-2013-0373

Frochot, I., \& Legohérel, P. (2014). Marketing du tourisme. 3e éd. Paris: Dunod.

Kasner, S. A. (no date). "The Concierge Mentality: Defining the Role of the Hotel Concierge". Hotel Business Review.

http://hotelexecutive.com/business_review/3294/the-concierge-mentality-defining-the-role-of-thehotel-concierge

Levere, J. (2011). The Virtual Hotel Concierge. The New York Times, June 28. http://www.nytimes.com/2011/06/28/business/28concierge.html

Martínez-Román, J. A., Tamayo, J. A., Gamero, J., \& Romero, E. J. (2015). Innovativeness and business performances in tourism SMEs. Annals of Tourism Research, 54, 118-135. http://dx.doi.org/10.1016/j.annals.2015.07.004

Mattsson, J., \& Orfila-Sintes, F. (2014). Hotel Innovation and Its Effect on Business Performance. International Journal of Tourism Research, 16, 388-398.

http://dx.doi.org/10.1002/jtr.1933

Menoux T. (2012, December). Concierges of luxury hotels: a traditional profession challenged by technological innovations. Paper presented at the 4th Asia-Euro Conference 2012 in Tourism, Hospitality \& Gastronomy, Selangor, Malaysia.

Mills, R., Rudd, D., \& Flanegin, F. (2009). “The Golden Keys” Being Served: Concierge Services and Customer Satisfaction. Journal of International Business and Cultural Studies, 1, 1-12.

Montargot, N. (2016). Digitalisation Advances and Hospitality Service Encounters, Symphonya. Emerging Issues in Management (symphonya.unimib.it), 1, 64-74.

http://dx.doi.org/10.4468/2016.1.07montargot

Nieves, J., \& Segarra-Cipre, M. (2015). Management innovation in the hotel industry. Tourism Management 46, 51-58.

http://dx.doi.org/10.1016/j.tourman.2014.06.002

Rico, J.C. (2016, May). La e-conciergerie dans l'hôtellerie: enjeux, rôle et implications. Paper presented at the 3rd annual conference of the Association Francophone de Management de Tourisme (AFMAT), Chambéry.

Shaw, G., Bailey, A., \& Williams, A. (2011). Aspects of service-dominant logic and its implications for tourism management: examples from the hotel industry. Tourism Management, 32, 207-214. http://dx.doi.org/10.1016/j.tourman.2010.05.020

Tang, T., Wang, M.C., \& Tang, Y. (2015). Developing service innovation capability in the hotel industry. Service Business, 9, 97-113.

http://dx.doi.org/10.1007/s11628-013-0220-z

Thomas, R., \& Wood, E. (2015). The absorptive capacity of tourism organisations. Annals of Tourism Research, 54, 84-99. 
http://dx.doi.org/10.1016/j.annals.2015.06.004

Wang, J.-Z., \& Wang, J. (2009). Issues, Challenges, and Trends, that Facing Hospitality Indusdtry. Management Science and Engineering, 3 (4), 53-58.

Withiam, G. (1993). American Concierges Set Service Standards. The Cornell Hotel and Restaurant Administration Quarterly, August, 25-29.

\section{Notes}

${ }^{1}$ Available at: https://www-03.ibm.com/press/us/en/pressrelease/49307.wss 